\title{
Foresight, Competitive Intelligence and Business Analytics - Tools for Making Industrial Programmes More Efficient
}

\author{
Jonathan Calof, Gregory Richards, Jack Smith
}

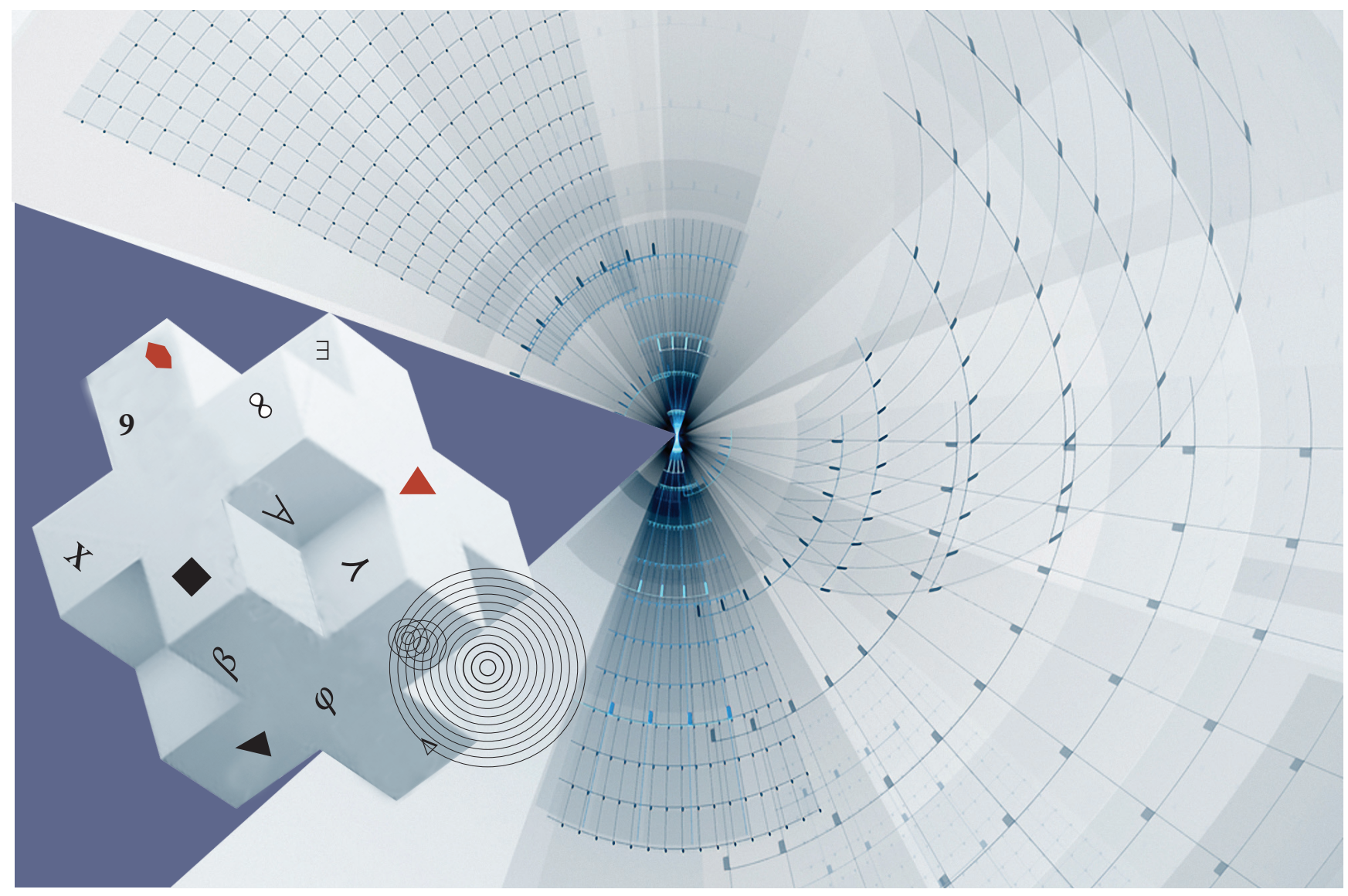

Creating industrial policy and programmes, especially in technology, is fraught with high levels of uncertainty. These programmes target the development of products that will not be sold for several years; therefore, one of the risks is that the products will no longer be in demand or will have been overtaken by more advanced technologies. In several cases, the authors have seen these programmes fail because the intended targets of the programme did not apply to use the programme funds (poorly targeted program) or did not use the programme properly. An integrated programme involving foresight, competitive intelligence and business analytics assists in decreasing the probability of the risks and problems described above, resulting in better designed and more successful industrial policy. These techniques can also be used to create a dashboard for monitoring programme use so that any problems can be corrected early on. The dashboard uses advanced analytics to assess programme applications and programme inquiries to assess whether the programme is being used properly. Via an integrated intelligence process, it monitors the external environment to ensure that programme assumptions in terms of what technologies are most appropriate remain valid. The dashboard relies on information available in open sources and available to the government.
Jonathan Calof - Associate Professor.

E-mail: calof@telfer.uOttawa.ca

Gregory Richards - MBA Program Director.

E-mail: richards@telfer.uOttawa.ca

Jack Smith - Adjunct Professor.

E-mail: jesmith@telfer.uOttawa.ca

\section{Telfer School of Management, University of Ottawa}

Address: 55 Laurier Avenue East, Ottawa, ON K1N 6N5, Canada

\section{Keywords}

foresight; competitive intelligence; business analytics; state programmes; profiling; monitoring; dashboard

\section{DOI: 10.17323/1995-459X.2015.1.68.81}

Citation: Calof J., Richards G., Smith J. (2015) Foresight, Competitive Intelligence and Business Analytics - Tools for Making Industrial Programmes More Efficient.

Foresight-Russia, vol. 9, no 1, pp. 68-81.

DOI: 10.17323/1995-459x.2015.1.68.81 
E stablishing industrial policy, and its ensuing programmes and industry assistance measures, is a task fraught with high levels of uncertainty. As will be shown in this article, an integrated programme involving foresight, competitive intelligence and business analytics should not only decrease levels of uncertainty and risk but also lead to greater probabilities of policy uptake by its intended audience and also early identification of industry opportunities.

This article is based on both academic scholarship and practitioner experience. The authors have been involved collectively in hundreds of industrial policy and programme projects globally and in many academic studies. Programmes and policies were approached through the field of competitive intelligence, business analytics and foresight. In this article, we define each of these disciplines and illustrate with an example of how and why the three approaches can be combined. Finally, we also discuss a dashboard that applies these concepts. To provide a common base for discussing the three domains in the context of programme development and monitoring, the following fictitious example is used. The Canadian government has noted that demand for and discourse about nutraceutical products is growing: this could represent an enormous opportunity for Canada. Accordingly, the government wishes to design a programme that will encourage Canadian companies to produce innovative nutraceutical products and technologies. It is hoped that this will stimulate products, which will then be commercialized, leading to jobs in the sector and wealth creation. Similar to other programmes, it is envisioned as a tax credit for eligible nutraceutical R\&D and commercialization investments.

\section{Foresight}

Foresight involves constructively bringing awareness of long-term challenges and opportunities into more immediate decision-making. 'Foresight is a systematic, participatory, future-intelligence-gathering and medium- to long-term vision-building process aimed at present-day decisions and mobilising joint anticipatory-preparatory actions' [For-Learn, 2014].

Foresight is neither prediction, nor does it estimate probabilities of particular pathways. Rather, it is about broadening our understanding about the drivers of societal change and becoming better prepared for the inevitable surprises ahead. Foresight normally starts with scanning to determine what is changing and why by anticipating plausible sources and origins of change, and seeking to understand the multiple complex interdependencies that motivate personal adaptation, organizational positioning — the capacity for adjustment, and societal evolution at a more macro level. Foresight then uses the various prospects of change to construct a range of plausible narratives or scenarios, and roadmaps to indicate basic directions.

Foresight asks ' what range of plausible futures might our organization have to be prepared for, and which strategies can help us build resilience and create adaptive capacity to anticipate and thrive in the turbulence of change?'

Foresight increases organizational agility through added resilience - alertness to trends, awareness of change drivers and readiness for potential shocks, issues, and challenges. Essentially, foresight employs a rehearsal approach to preparedness by addressing the 'what if scenarios.

Foresight establishes a context (i.e. the boundaries and possibilities of what are deemed plausible narratives) for both the extent and speed of potential change and the adaptive risks of a designated sector, emerging market or technology domain.

\section{Applying Foresight to Nutraceuticals}

So how might the government apply foresight to nutraceuticals? How could foresight be used to address concerns about the long-term competitive viability of the nutraceuticals sector and approach the challenges of a rapidly changing technology landscape? More specifically, how should a government industry department, with an already successful track record of nurturing the development of new nutraceutical companies, approach the complexity of deciding whether, when and how to invest in a new area of technological progress with potentially transformative applications?

A first step would be to consult technology and environmental scanning reports similar to those categories highlighted in Table 1 (see below). Table 1 was developed by Ozcan Saritas and Jack Smith as a contribution to the European Commission's Future Technologies Assessment Conference overview report on 
the Big Picture Survey. The survey used five standard STEEP-type categories (four presented in the table) and then three sub-categories for each. The technology areas are embedded in each sub-area, and/or featured in the two highlighted areas under Science and Technology.

This foresight technique indicates that there are real uncertainties about what applications might soon become both technically feasible and economically viable and whether there may be toxicological risks. Applying this within the nutraceuticals sector found that a growing global market in nutraceuticals already exists and that the application of molecular scale nano-engineering was progressing fast and could create enormous growth if and when successfully commercialized. Significant uncertainty remains, however, around which countries and producers could do this when and how.

To better understand the broader context of these uncertainties, two additional foresight techniques are frequently employed: scenarios and technology roadmaps. Jack Smith and Ozcan Saritas [Saritas, Smith, 2011] and Rafael Popper [Popper, 2008] discuss the foresight analytical techniques and methods for selection in more depth.

Scenarios explicitly build upon identified key uncertainties. The aim of scenarios is to develop future oriented situational narrative visions and glimpses of plausible future operating environments that can reveal business challenges as well as opportunities stemming from the resolution of the identified uncertainties. Therefore, by using this technique it is possible to anticipate actions in advance of your competitors.

In the area of future nutraceutical applications, four representative scenarios could be derived from, for example, the dual uncertainties of the rate of science and technology (S\&T) progress and the pace and performance results of regulatory oversight. These drivers are based on past scenario projects in similar areas in which the authors have been involved. In this example, four different scenarios emerged: called 'nutri-slow', 'nano-go', 'nutri sue', and 'nano promo'. Note that two of the scenarios involve nano-technology. The most significant issue was that regardless of whether oversight was uncertain or high, as soon as the dynamics for S\&T progress become rapid, the result moves into the nano-driven zone. To apply this to the developed programme, we first need to determine where we are now (in 2014-2015); where we seem to be heading; and whether this can or should be changed in some manner through policy actions. So what messages are the foresight scenarios conveying?

- The current market in 2014 for conventional nutraceuticals is projected to remain sluggish. Yet it could soon become highly vulnerable if (as expected by leading scientists) nano-scale design and production advances enable producers in other countries or markets to shift into what is described as fast and transformative. This situation would create more competition;

- There are understandable uncertainties associated with R\&D and regulatory approval, issues which will have to be closely monitored. If the new nano techniques are able to obtain approval, then current production platforms will become as obsolete as floppy disks competing against flash drives;

- While timelines are imprecise in foresight, it is clear that the key change factors - represented by the scenario drivers and uncertainties - are going to be influencing the next business cycles of nutraceuticals.

Technology roadmaps are more specific to the needs of most business enterprises than scenarios (which are typically initiated by governments). They are typically employed to further reduce uncertainty. First, roadmaps are managed by industry. Second, they have more immediate and specific decision timelines

\section{Table 1. Results of a foresight STEEP exercise}

\begin{tabular}{|l|l|l|l|}
\hline Society and culture & $\begin{array}{l}\text { Social norms, education, } \\
\text { information and knowledge society }\end{array}$ & $\begin{array}{l}\text { Demographics, urbanization, } \\
\text { population health and } \\
\text { migration }\end{array}$ & $\begin{array}{l}\text { Equity, ethical, moral and legal } \\
\text { issues }\end{array}$ \\
\hline Science and technology & Science, culture and discoveries & Technology progress & $\begin{array}{l}\text { Innovative, transformative, } \\
\text { applications \& products }\end{array}$ \\
\hline Energy & $\begin{array}{l}\text { Current energy use, peak oil, } \\
\text { Efficiency and security }\end{array}$ & New and renewable resources & $\begin{array}{l}\text { Non -renewable energy } \\
\text { alternatives }\end{array}$ \\
\hline Ecology-Economy & $\begin{array}{l}\text { Stage of global finance, trade, debt } \\
\text { and related globalization issues }\end{array}$ & $\begin{array}{l}\text { BRIC rapid development } \\
\text { economies }\end{array}$ & $\begin{array}{l}\text { Climate change, global warming = } \\
\text { sustainable ecology, new economy }\end{array}$ \\
\hline \multicolumn{2}{|l|}{ Source: [Saritas, Smith, 2008]. } & & \\
\hline
\end{tabular}


for investment. In other words, they outline what specific investments will be required and when (e.g. new $\mathrm{R} \& \mathrm{D}$; equipment, training and skills development, emerging market research) to acquire the needed agile capacity to realize the opportunities and reach the business destination before others.

Further analysis into nano composite new materials leads us to the possibility of nano-based nutraceuticals or nano-nutraceuticals, which would likely score highly with moderate risk in terms of policy barriers.

Although technology foresight shows that several nano-nutraceuticals have already been commercialized, risk remains nevertheless. This is mainly because the regulatory environment has not yet fully rendered its judgements and concerns about the health implications surrounding the ingestion of nano-based products.

A typical foresight insight or conclusion from technology roadmaps is as follows:

- The matrix analytical framework suggests positive potential from the new technological opportunities;

- Further R\&D will be required, especially in terms of the regulatory hurdles;

- To succeed - or at least be early entrants in the emerging nano-based nutraceutical design and production platforms - excellent scientific capabilities and equipment are needed. Aspiring firms must plan and recruit for these in advance if they want to be competitive.

In conclusion, the use of foresight enables a programme recommendation for nano-nutraceuticals to be drawn up. This comes about through STEEP and scenarios. A nano-nutraceutical roadmap provides the information needed to focus the programme on the specific kinds of research and issues such as regulations that should be addressed.

\section{Competitive intelligence}

Definitions of competitive intelligence (CI) focus either on the objective of CI or how CI is done (process definition). For example, the Strategic and Competitive Intelligence Professionals (SCIP), a global association of competitive intelligence practitioners defines $\mathrm{CI}$ as 'a necessary ethical discipline for decision making based on understanding the competitive environment' [SCIP, 2014]. While this does not define CI, it does describe its objective. Similarly, Professor Du Toit defined it in terms of its objective: 'Competitive intelligence (CI) is a strategic tool to facilitate the identification of potential opportunities and threats.' [Du Toit, 2013]. Salvador and his colleagues wrote that the objective of competitive intelligence was to support innovation [Salvador et al., 2013].

Others have defined competitive intelligence in terms of its process i.e. how it is created. For example, Kahaner wrote that CI is 'a systematic program to collect and analyze information about competitors' activities and general business trends to achieve the goals of the company. Moreover, CI consists of identifying intelligence needs within an organization, collecting data from primary and secondary sources, evaluation, and analysis' [Kahaner, 1997, p. 16]. Kahaner's definition fits with the 'wheel of competitive intelligence' concept, which posits that $\mathrm{CI}$ is developed in a systematic and ethical manner involving planning, collection, analysis, communication and management.

The field of CI has a very long and rich academic and practitioner history, with academic literature citations first appearing in the 1950s and company practices noted in the $15^{\text {th }}$ and $16^{\text {th }}$ century [Juhari, Stephens, 2006]. Thus, it can hardly be called a new discipline. However, with the increasingly competitive environment, government and business have been turning to a greater extent to competitive intelligence to better understand their environment and develop better programmes and strategies. In a survey carried out by the Global Intelligence Alliance (GIA), the percentage of respondents with CI functions grew from $63 \%$ to $76 \%$ in two years; moreover, the third of surveyed companies which did not have any CI operations stated that they intended to launch such an operation within 12 months [GIA, 2011]. A study done by the American Futures Group consulting firm found that $82 \%$ of large enterprises and over $90 \%$ of the Forbes top 500 global firms adopt CI for risk management and decisions [Xu et al., 2011]. The Xu study also pointed to a high value of the CI industry: by the end of the $20^{\text {th }}$ century, the study estimated that the overall production value of CI industry had reached 70 billion USD [Ibid.]. SCIP estimates its value at a more conservative 2 billion USD a year [SCIP, 2014]. Regardless of the figure used, 
studies do report that the amount spent on $\mathrm{CI}$ is growing and that the activity was paying off. A GIA study in 2013 reported that decision making was 15\% more efficient in companies with a CI function in place, and $80 \%$ of surveyed companies said the investment was paying off in terms of the return on investment [GIA, 2013].

In trying to understand competitive intelligence practice, various organizations have surveyed CI practitioners. The GIA (www.globalintelligence.com) carries out these studies on a regular basis, two of which we described above. Academics throughout the world have looked at their country's CI practices, sometimes comparatively (see for example, [Wright, Calof, 2006; Du Toit, 2013; Bergeron, 2000]. In 2005, the Competitive Intelligence Foundation supported a global study on competitive intelligence practice [Fehringer et al., 2006]. One of the findings of this study was that CI was being used to help make many different kinds of decisions including market entry, product development, $\mathrm{R} \& \mathrm{D}$, corporate development etc. (Table 2). The study also pointed to a broad range of analytical methods used for developing CI (Table 3). Consistent with competitive intelligence theory, the information for developing CI primarily came from the organization's own employees, followed by industry experts and customers. Conferences and trade shows were also common places to gather primary sources of information. In terms of secondary sources, $97 \%$ of respondents mentioned online and print publications; the Internet and fee-based online subscriptions were also highly used $(85 \%$ and $84 \%$, respectively, said this was a very important source or these were very important sources).

Competitive intelligence has several sub-domains or speciality fields. These include competitor intelligence (intelligence focused on competition); sourcing intelligence (intelligence used in the human resource function); and competitive technical intelligence (CTI), which is of the most relevance for this article. CTI is competitive intelligence within the R\&D arena [Herring, 1993; Ashton, Klavans, 1997]. Ashton and Klavans defined it as 'business sensitive information on external scientific or technological threats, opportunities, or developments that have the potential to affect a company's competitive situation' [Ashton, Klavans, 1997, p. 11]. Literature from as long ago as the 1960s discusses CTI. For a more detailed look at CTI, see [Calof, Smith, 2010].

\section{Government use of competitive intelligence}

While much of the competitive intelligence literature focuses on the use of this activity by companies to support economic and technical decisions, there is a stream of literature that looks at its importance for governments. Growth in government use of CI led to SCIP allocating a conference track to government and $\mathrm{CI}$ in 2004. Driving the increased use of CI by the public sector are the difficult financial, economic and political decisions facing public managers and the need for and availability of CI techniques to help with these decisions [Dedijer, 1994; Watson, 1997; Parker, 2000; Hamilton-Pennel, 2004; Calof, 2007]. Calof and Skinner looked at CI within the Canadian government, noting that it was used extensively in various departments for policy development [Calof, Skinner, 1999)]. At a technical intelligence level, Fruchet wrote that the CTI group at the National Research Council (Canadian government organization) 'provided technology intelligence products and services to business and market development customers in both the NRC research institutes and the Industrial Research Assistance Program' [Fruchet, 2009, p. 37]. Competitive intelligence programs

Table 2. Cl-based types of decisions (as a percentage of total number of surveyed)

Question: What business decisions do your department's CI decisions support?

\begin{tabular}{|c|c|c|c|c|c|}
\hline \multirow[t]{2}{*}{ Decision supported } & \multicolumn{5}{|c|}{ Types of answers } \\
\hline & Frequently & Sometimes & Rarely & Never & Don't know \\
\hline Corporate/business decisions & 54.1 & 32.6 & 8.5 & 3.2 & 1.6 \\
\hline Market entry decisions & 38.9 & 38.3 & 13.6 & 5.7 & 3.5 \\
\hline M\&A, due diligence, Joint Venture & 25.9 & 31.3 & 22.2 & 14.6 & 6.0 \\
\hline Product development & 36.8 & 37.3 & 16.6 & 5.7 & 3.6 \\
\hline Regulatory or legal & 12.9 & 30.6 & 30.5 & 17.4 & 8.6 \\
\hline Research or technology development & 24.4 & 39.2 & 21.0 & 10.3 & 5.1 \\
\hline Sales or business development & 48.7 & 35.8 & 10.3 & 2.4 & 2.8 \\
\hline
\end{tabular}


Table 3. Intensity of using different analysis techniques

(as a percentage of total number of surveyed)*

\begin{tabular}{|c|c|}
\hline Technique & $\%$ used \\
\hline $\begin{array}{l}\text { Strategic Analysis techniques } \\
\text { BCG Matrix } \\
\text { Industry analysis ( } 5 \text { forces) } \\
\text { Strategic groups } \\
\text { SWOT } \\
\text { Value chain }\end{array}$ & $\begin{array}{l}46.2 \\
78.1 \\
64.3 \\
90.3 \\
65.6\end{array}$ \\
\hline $\begin{array}{l}\text { Environmental analysis } \\
\text { Issue analysis } \\
\text { Scenarios } \\
\text { Stakeholder } \\
\text { STEEP }\end{array}$ & $\begin{array}{l}69.1 \\
68.6 \\
61.8 \\
59.9\end{array}$ \\
\hline $\begin{array}{l}\text { Financial analysis } \\
\text { Financial ratio } \\
\text { Sustainable growth rate }\end{array}$ & $\begin{array}{l}76.1 \\
66.5\end{array}$ \\
\hline $\begin{array}{l}\text { Competitive \& customer } \\
\text { Blind spot } \\
\text { Competitor } \\
\text { Customer value } \\
\text { Customer segmentation } \\
\text { Management profiling }\end{array}$ & $\begin{array}{l}54.3 \\
90.1 \\
74.2 \\
79.6 \\
70.5\end{array}$ \\
\hline $\begin{array}{l}\text { Evolutionary analysis } \\
\text { Experience curve } \\
\text { Growth vector } \\
\text { Product life cycle } \\
\text { Technology life cycle }\end{array}$ & $\begin{array}{l}48.8 \\
47.0 \\
68.2 \\
65.0\end{array}$ \\
\hline
\end{tabular}

have been used for stakeholder analysis, treaty negotiations, identification of international priorities, developing technology programmes and policy, and more.

Canada is not unique in government use of CI processes to develop programmes and policies. Bonthous examined the French government's use of CI for policy and programme development [Bonthous, 1995], while Gilad looked at the Japanese model, these are but a few of government use CI studies [Gilad, 1998].

\section{Foresight as a complement to CI and CTI}

Calof and Smith developed a framework for R\&D project selection that combined foresight and competitive technical intelligence. In the article, they describe the two as complementary: 'Today's decisions will shape the environments of tomorrow whether in business or government, and however one acquires the best intelligence, new market characteristics and estimates and a disciplined imagination of plausible situations, the agility of positioning and response can be substantially increased through a complementary approach that, if successful in capturing the many dimensions of future risk, will represent an integrated capability' [Calof, Smith, 2010].

The perspective of foresight is 'outside in'. In other words, it looks outside the frame of any organization or country strategy and asks what the future environment looks like. Competitive intelligence, on the other hand, starts with an existing strategy and asks how the environment will affect the success of this strategy. Foresight tends to be long-term in outlook (in some cases, 50 years into the future), while the time frame for competitive intelligence is considerably shorter. The timeline for CTI is generally longer than that of other forms of competitive intelligence but far shorter than foresight. Calof and Smith reviewed several CTI studies and found that they generally had a time frame of between 3 and 10 years [Ibid.]. Foresight broadens understanding and identifies pathways. In contrast, competitive intelligence takes those pathways and understanding and seeks estimates, probabilities and forecasts within the short to medium-term to help companies adapt their strategies to the most likely environmental context. Competitive intelligence adopts a predictive approach to scoping future risks that seeks to provide direction to decision makers on the implications of new and emerging technologies and their prospective markets. The expected outcome is more effective organizational development and competitive strategies. Together, foresight and CI offer a package of methodologies, 
including primary and secondary collection approaches, facilitation methods, a variety of robust analytical methods, an ability to work with qualitative information, and a clear focus on understanding the external environment. Hence, foresight and CI are highly complementary.

\section{Applying competitive intelligence for the design of the nano-nutraceutical programme}

First, foresight provides the decision maker with two very valuable inputs: rather than the generic concept of nutraceutical, the scenario exercise focused on nano-nutriceutical. Second, roadmapping identified some of the issues that should be addressed on the path to commercialization (e.g. regulatory and company requirements in, for example, $R \& D$ capabilities.

How would a CI professional seek to develop the programme? What would their unique contribution be that is distinguishable from foresight's contribution? As noted in the previous section, CI would undoubtedly adopt a shorter term orientation, focused more on the strategy.

Foresight recommended that the Canadian government develop a programme that will encourage Canadian companies to engage in appropriate nano-nutraceutical research and commercialization. If the objective is to encourage companies to do this kind of research, CI would may ask two questions:

1. Are Canadian companies willing to engage in this kind of research? (interest and capacity);

2. What incentive will they require to engage in this kind of activity? For example, a loan guarantee? If so, at what percentage? A tax credit? If so, at what level? Grant programme?

In general, the aim of this type of government research assistance programme is to encourage companies to change their $\mathrm{R} \& \mathrm{D}$ behaviour to match the government's desires. How do you get a company to change its behaviour? There are many analytical techniques in CI (see [Fleisher, Bensoussan, 2002] for a description of some of the more popular ones). For a question like this, CI turns to a technique called profiling which involves putting together a detailed psychological based assessment of the target. Profiling seeks to determine how the target will most likely react. In understanding the target, profiling is also able to find out what someone has to do to get the designated reaction from the target. A competitive intelligence profiler would seek to develop detailed profiles on the companies that would be likely to adopt the government's research programme. The profiler would be looking for information about the company's research decisions, including what drives these decisions and the target's risk orientation. The profile needs to be designed to determine both potential companies' interest in doing nano-nutraceutical research and the kinds of incentives that would encourage a company to make this decision. Most of the information required for this kind of profiling should be readily available to the government. For example, the companies being profiled may have already applied for programmes, and associations may have presented reports and recommendations to the government. Other ways of getting information include examining past programmes, checking programme files, and having discussions with programme officers who oversaw the programme.

Table 3 (intelligence analytical techniques) lays out many of the more popular competitive CI analytical techniques. Most of these come under the category of strategic analysis and environmental analysis. The reason that environmental and strategic analysis techniques are so popular is they get at the heart of what decision makers need to know: is the market profitable and what does the company need to do to capture those profits. Therefore, a CI practitioner will want to do a market profile. Table 3 also lists some evolutionary techniques that look at technology direction within an industry. These are important because the CI officer of a company wants to ensure that the kind of research encouraged in that company is appropriate for the future environment. If it takes five years for companies to conduct the research and get something ready for commercialization, then the CI practitioner will seek to understand where the company is likely to be in the next five years and in which direction the industry is heading. Another question the CI practitioner looks at is what their company's competitors are likely to do over the next five or more years (it is unlikely, for example, that they will still be developing and using today's technology for five or more years).

One of the more popular techniques used for this purpose is called timelining. Competitive intelligence realized long ago that there were logical sequences to 
any major shift in a marketplace. For example, long before a new technology hits the market there had to have been manufacturing activity - and before that, testing, research, and so forth. Each of these sequenced steps leaves information that those interested can view. For example, research activities are accompanied by patents and sometimes poster sessions at conferences. It is no wonder that several companies have told employees that when they see someone new at a trade show, they should inform the management. The new player could be a potential customer, competitor, or supplier who wants to learn about the industry.

Similarly, techniques such as science mapping have been developed to look at what research communities are coming together to better predict the direction of research. While projecting 10 years out is very difficult, timelining makes things a little more certain by looking at what activities have already been done. The idea here is to identify what is currently happening in the industry at a global level and place it on the timeline. The information is taken from secondary sources such as magazines and various online databases, yet is also more commonly found by attending industry events. Event intelligence is a growing discipline within CI and involves collecting data at conferences, tradeshows, workshops, and other events to gather this kind of information. Using event intelligence, it should be relatively straightforward to identify how fast and transformative science currently is, and where various companies are positioned on the timeline. Take, for example, the following quote from Forbes magazine:

'Nestle may also be exploring nutraceuticals in the form of nano-capsules that deliver nutrients and antioxidants to specific parts of the body at specific times. The technology turns previously insoluble nutrients into nano-sized particles that can be released into the body and properly absorbed, with big potential benefits for a whole new kind of health food.' [Wolfe, 2005].

Clearly the company Nestle is well along the development curve. If this is where they potentially were in 2005 , the CI officer will use timelining to project where Nestle is likely to be in 2014. Based on this prediction, the CI officer can assess the likely state of Nestle's research and commercial offerings in 2020 (the targeted commercialization period envisioned by the programme). Whatever focus within nano-nutraceuticals that the programme will have, the programme should lead to a better result in products that are technologically as advanced or even more so than the products of Nestle and others that will be on the market. Having completed the analytical techniques mentioned in this section, the CI professional is now ready to make specific programme recommendations. Knowing the profile of targeted companies including these companies' risk orientation, the analysts can make incentive recommendations. With the market analysis, they can further refine the incentive. For example, if the market is growing and profitable, a lower incentive rate should be made. If the target companies are highly risk averse and the opportunity is more distant, a larger incentive would be recommended. In the hypothetical case with nano-nutraceutical research that we study in this article, nano-nutraceutical research takes a long time and has much regulatory uncertainty around it. This same field of research has widespread concerns about consumer acceptance of nano-nutraceuticals. Hence, in these sorts of situations, a higher incentive will be required. Consistent with the market and profiles, a recommendation of a grant or cash based incentive would be made. To some, a tax credit is more appealing than getting a grant or cash when levels of risk are higher. Finally, the science mapping and timelining should provide the government with the CI needed to further target incentives to those areas of nano-nutraceuticals that provide better opportunities for Canadian companies.

\section{Business Analytics}

Business analytics is in vogue as a buzz word for the use of data to inform decision making in organizations [Davenport et al., 2010]. In its Big Data incarnation, it is tied closely to the use of data mining techniques to analyse large complex data sets that might provide insights if mined properly. In reality, business analytics has been used in organizations for many years and hundreds of different techniques are available - all focused on optimizing one or more organizational outcomes. Ford Motor Corporation, for example, applied the basic notion of business analytics in 1914 when Henry Ford decided to more than double employee wages. Conventional wisdom assumes that increasing the cost of production will lead to higher prices and reduced demand. Ford, however, noted an increase in demand by approximately 60\% between 1914 and 1916, 
while prices dropped by $33 \%$ during the same time period. The sound application of business analytics enables managers to glean insights that might not be immediately obvious.

Analytic techniques might be categorized into three main types: 'describe, prescribe and predict.' Many organizations, in both the private and public sectors, are very good at descriptive analytics: charts and graphs about organizational phenomena such as how many companies took advantage of a government sponsored research credit programme, the location of companies, the amount of funds leveraged etc. Most organizations, however, are less capable of prescriptive analytics which could, for example, identify how best to allocate funds in order to optimize a certain organizational objective.

Predictive analytics has become the 'holy grail' of analytics. It is being used in some organizations. One of the most mature areas is credit risk where, by analyzing characteristics such as a borrower's past behaviour or income flows, it is possible to get accurate predictions about the likelihood of default. In policy development, the notion of 'evidence-based policy' is founded on the idea of predicting the likely impact of policy interventions. At the moment, these predictions are subjective estimations. As we will discuss below, however, much is being done to better use data to make policy decisions.

\section{Business analytics in government}

Government organizations worldwide have embraced the notion of analytics. Well-established applications of analytics in government organizations include passenger screening and tracking of aircraft in the security field, and the use of crime analytics to detect and ultimately prevent crime [IBM, 2013]. While the US appears to be ahead of many countries in applying analytics to the business of government, other countries such as Korea, Japan and Singapore have adopted risk assessment analytic approaches, intelligent traffic systems, and analytics driven monitoring systems to help anticipate and prevent occurrences such as epidemics and famine.

How does business analytics play into the scenario discussed above? If a policy initiative is to encourage businesses to invest in nano-nutraceuticals, a variety of analytic techniques can be used to anticipate the actual take-up of the provisions of the policy. Now, we will discuss two relatively simple techniques to illustrate how foresight, competitive intelligence, and business analytics can be integrated within the context of national policies.

Two aspects deserve consideration: the estimation of the expected value of the policy and the evaluation of the likelihood that participants who are expected to avail themselves of the policy will behave in ways that will provide the expected value.

Econometric models are typically used to estimate the social and economic benefits to be derived from a policy. These models, however, rely on data gathered from stakeholders related to the policy environment. One relatively new approach to gathering data is 'sentiment analysis.' This approach, based on the analysis of qualitative information appearing on millions of websites and blogs from the intended audience, helps to identify opinions related to the outcomes promoted by the policy. In addition to forecasting techniques such as scenario planning and roadmaps, sentiment analysis can provide guidance as to the attitudes prevalent in a particular population. It can be used for example, to predict the expected take-up of the policy's provisions. Assuming that expected policy outcomes include the launch of businesses developing nano-nutraceutical products, the analysis of consumer sentiment can provide clues about potential customer acceptance.

Two categories of analytics can be applied. Descriptive analytics would outline the percentage of posts that are positive or negative related to the policy in question. Based on this data, predictive analytics - using 'Big-Data' techniques such as clustering for example - can separate the population that is posting about the policy into different groups based on characteristics such as age or geographic location. Based on this grouping, different simulations can be developed to anticipate the likely reaction based on changes to certain aspects of the policy. Figure 1 illustrates these ideas.

Dark blue icons represent those opposed to the policy, while green icons represent people who support it (Figure 1). The graph shows a clustering by age and geographic categories. In this case, it indicates that aspects of the policy needs to be tweaked to better appeal to younger people in location A. Depending on 
the information available about people in the various cells (younger, older, location A, location B), data mining tools can be used to predict whether such policy changes are likely to appeal to each of the cells in the graph.

Using such predictive concepts, government policy makers can anticipate how the businesses they expect to participate in the initiative will respond. For example, intelligence through profiling may identify $40 \%$ as the likely rate for the grant programme based on looking at past programmes and company profiles. In contrast, analytics will refine this prediction by developing algorithms to look at the risks associated with the research and the companies' risk attitudes.

With this information in hand, we can go one step further and simulate the decision process used by businesses who might take advantage of the programme. Businesses typically invest in new products in order to make a profit. Investment decisions can be quantified through the use of a variety of analytic models, one being the 'net present value' (NPV) calculation. This approach discounts future expected cash flows of an initial investment to estimate potential returns. The calculation is as follows:

$$
\left[\Sigma_{t} \text { Cashflow }_{t} /(1+\mathrm{i})^{t}\right]-\text { Investment }
$$

Where $i=$ expected discount rate during the time period and $t=$ number of compounding periods.

As a greatly simplified example, suppose the business would need to borrow 500,000 USD for the investment at 7\% interest rate to be paid in full after three years. Using the left side of equation 1, the company estimates cash flows for the first three years after full production of approximately 600,000 USD. The future value of the loan (adding the 7\% interest compounded over three years) is approximately 612,000 USD. Therefore, the company would likely not make the investment.

With a government programme providing a guarantee for the funds borrowed, assume the interest rate is reduced to $3 \%$. The future value of the loan is now approximately $\$ 546,000$. The decision rule for NPV calculations is to invest in projects with a positive cash flow; therefore at $3 \%$ the investment will likely be made.

Ultimately, using approaches such as that described above to simulate a business' decision model can help policy makers better predict uptake and more accurately define the parameters of a policy.

\section{Analytics conclusion}

A wealth of tools and techniques are available to policy analysts who would like to predict the likely outcomes of a policy. Data scientists, given the right type of data and data that is well-organized, can analyse and predict likely outcomes [Provost, Fawcett, 2013]. This capability will enable policy analysts to uniquely fine tune policies to improve the chances of realizing the results expected. As the technology available for Business Analytics improves and the techniques available to data scientists evolve, more government organizations will make use of such tools to monitor and manage operational activities. Applying such

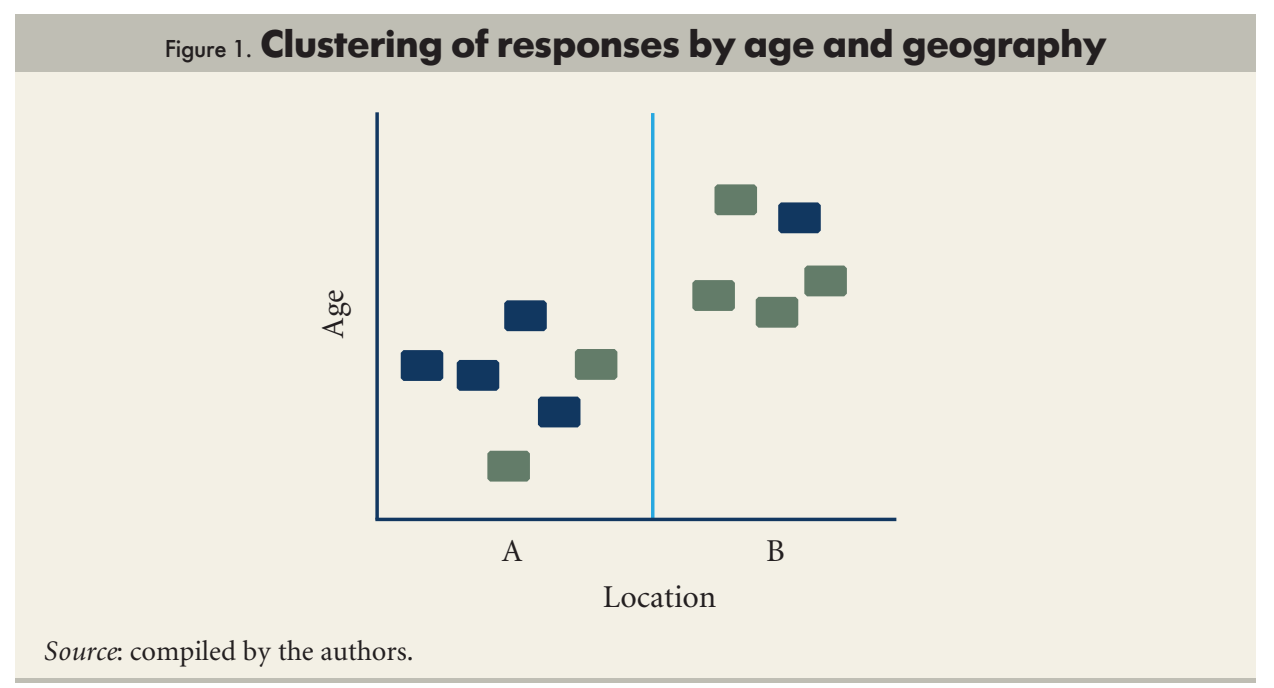


empirically-based predictive approaches to policy initiatives is still in its infancy but the opportunities are quite compelling.

\section{The Combined Approach}

Foresight and Competitive Intelligence offer a collection of methodologies including primary and secondary data collection approaches, facilitation methods, a variety of robust analytical methods, an ability to work with qualitative information, and a clear focus on understanding the external environment.

Business Analytics contributes modeling capabilities, methods for dealing with massive amounts of quantitative data, emerging text analysis sof tware for qualitative data, a variety of proven internal indicators that have been used for dashboards, and a rich history of primarily internal organizational analysis with a growing literature on customer analysis.

All three domains (foresight, competitive intelligence and business analytics) are used to provide decision making support and have complementary analytical techniques that allow the decision maker to better understand the external environment including key stakeholders. The combination of the three approaches is also useful for reducing the risk of designing a flawed programme. Omitting any one of these approaches increases the risk of programme failure as the programme developer would be missing out on what could be a critical analytical component needed for the design of the programme.

Combining the three approaches is starting to appear in some government programmes. For example, in 2011 the United States government started a defence programme called FUSE (Foresight and Understanding from Scientific Exposition). The programme funds the development of 'automated methods that aid in the systematic, continuous, and comprehensive assessment of technical emergence using information found in published scientific, technical, and patent literature' [Office of the Director of National Intelligence, 2014]. Specific research areas include text analytics, knowledge discovery, big data, social network analysis, natural language processing, forecasting, and machine learning. According to [Smalla et al., 2014] the programme has a clear link with competitive technical intelligence. The techniques referenced and the automated analysis intent fall within the domain of business analytics but the intent is to create foresight-based conclusions. This is a good example of the techniques from business analytics and competitive intelligence being needed for foresight purposes. In this example, combining the domains is crucial as each has unique analytical approaches that are necessary for getting the bigger picture.

\section{Developing the dashboard and monitoring mechanisms}

The purpose of a programme/policy dashboard is to give early warning of necessary changes based on external environment signals. Table 4 is a fictitious example of a dashboard for the hypothetical nutraceuticals programme we have outlined earlier in this article. The initial design was based on long-term analysis through foresight, short and medium-term analysis through competitive intelligence, and further refinement through analytics. Ultimately, however, these techniques were used to reduce programme risks and not eliminate them. Accordingly, the idea of a programme dashboard is to monitor the environment on an ongoing basis for three reasons:

1. To check if we were correct in our analysis of the potential programme users and that the programme is being used as envisioned in the programme designed by the appropriate users and for the appropriate technology development;

2. To verify that we were correct in our analysis of the nano-nutraceuticals market and that the underlying profitability, technology developments and so forth are consistent with what was assessed in the initial analysis. In addition, we want to check that the timeline projected for the industry also hold.

3. To ensure that the longer term scenario and roadmap projected for the programme design also holds.

A change in any of these could result in the programme not attaining its desired outcomes. Finding out about changes in any of these early enough can lead to programme changes that will improve its effectiveness or stop the programme if it is not meeting its objectives. 
Early Outcomes

Advice and counselling

Inquiries

Applications

Intermediate Outcomes

R\&D activity

University and college training programmes

Business clusters formation

Patenting

Requests for commercialization funding

Long-Term and Environmental Factors

Sentiment Indicators-Business

Sentiment Indicators-Consumers

Technology watch

Grey literature development

Timeline and roadmap milestones

Roadmap and scenario monitoring

Source: compiled by the authors.

Developing the programme dashboard and its ensuing key performance indicators (what needs to be monitored) starts with competitive intelligence and timelining. In this case, the programme developer needs to look at all the activities (and activity measurements) between announcing the programme and the final outcome, successful commercialized products and jobs. Based on our experiences with government programmes, these are the activities that are embedded in the timeline:

1. Programme inquiries. Once a programme is announced and before the application process opens, it is normal for companies to ask local government officers for more information about the programme, advice and counselling on applying for the programme.

2. Applications / proposals. Normally, several months after the programme is announced and after enquiries, companies submit applications.

At this early stage, the first two steps as identified in a competitive intelligence timeline exercise can be put on a dashboard and monitored. For example, for a technical programme in Canada it would be expected that inquiries would be made to the National Research Council officer, to Canadian Business Service centres, and in the case of some regions of Canada, to regional development officers. As part of the dashboard exercise, these individuals could be asked to enter the emails received about the programme and summaries of conversations into a database. These could be analysed using content analytics sof tware. Applications/proposals when received can be subject to content assessment. Software could be used to look at the kind of development proposed (is it what the programme envisioned?) Analysis could also be done on whether the number of applications meets the desired level, and where the applications are coming from (regional distribution, type of companies, etc). At this stage of the programme, problems identified through the analysis of dashboard data could be investigated and the programme could be modified accordingly. Perhaps the programme is not being advertised properly (a problem we have seen before) or perhaps the incentives provided are not significant enough to encourage the desired kinds of research. We have also seen situations where the incentive was appropriate but there was no interest in doing research in the area targeted by the programme. This part of the dashboard focuses on validating and monitoring the company profiles.

In the dashboard (Table 4), the colour represents the extent to which the environmental element being measured meets the initial projections and needs of the programmes. Green would mean it is consistent with initial estimates and 
expectations, yellow slightly off (caution), and red would be significantly off or cannot be measured yet. In this example, early stakeholder questions and interest were initially as required by the programme (signified by green) in period 1 and period 2. Yet, in the third period it had turned yellow (caution) meaning that it is going off requirements either on a regional basis or type of questions (this would need to be investigated and if needed would signify the need for programme corrections). Advice and counselling initially started in the yellow (caution zone) but moved to green in the second and third measurement periods, Assuming the right companies are asking the correct questions and applying for funds to develop the targeted technologies for commercialization, what comes next in the timeline? What gets measured and put on the dashboard next? In this simplified example, alongside with the abovementioned ones, further intermediary steps include:

3. R\&D activity. Next should be hiring activities and R\&D;

4. University/college training programmes. If this is a new area of research, appropriate labour availability should be an issue thus there should be development of training programmes to support the companies' demands. Without the appropriate labour, the development and commercialization activities cannot occur;

5. Business clusters formation;

6. Patenting;

7. Requests for funding for commercialization.

All the activities in the intermediate outcomes are needed for the final outcomes of the programme to be realized.

The final item to place on the dashboard is monitoring of the external environment in terms of the underlying profitability, demand, interest, and all the factors examined in our earlier analysis. This concerns monitoring the factors that underlie the strategic, environmental, and evolutionary analyses. Environments do change and with it the rationale for the initial programme. A few of the items that could be on the dashboard include:

- Sentiment indicators - Business. This is an analytics approach assessing social media data for signs that interest from companies in the targeted areas is growing during the programme's duration;

- Sentiment indicators - Consumers. This is an analytics assignment assessing social media for signs that consumers' interest in the targeted areas (level 1 and 2 nano-pharmaceuticals) is growing during the programme's duration. Biofoods encountered a serious blow when consumer concerns dominated discussions;

- Technology watch, grey literature analysis, timeline and roadmap milestones. Governments need an ongoing technology watch programme, including grey literature analysis to examine if there are unexpected developments. For example, another country might have developed disruptive technology in the area or might have invested a lot of resources to move the technology forward at an accelerated rate. These kinds of developments need to be watched;

- Roadmap and scenario monitoring. Similar to timeline and roadmap milestones, these would need to be an ongoing effort to watch for signs of which scenario was emerging and whether the milestones are being met (or not) on the roadmaps.

Information for the dashboard is generally readily available. The information required for the sentiment analysis could come from social media as well as assessments of emails sent to the government agencies about their programmes. Grey literature analysis is well developed as an analytical discipline and appropriate databases would need to be accessed (all open source, public databases). Technology watch, timeline, roadmap, scenario etc. information would be gathered from several sources including:

- Ongoing foresight and competitive intelligence projects. The government could run Delphi's on an ongoing basis to test the longer term assumptions and commission additional competitive intelligence projects;

- Organized data collection at conferences and trade shows. For example, the Bio trade show would have workshops, booths, presentations and participants with the appropriate knowledge of developments in nano-nutraceuticals. 


\section{Conclusions}

As mentioned at the start of this article, industrial policy is fraught with uncertainty due to its reliance on external environmental elements for its success. Foresight, competitive intelligence and business analytics taken together provide a toolkit to better understand this uncertainty and can help lead to more successful industrial policy. Foresight and Competitive Intelligence - focused on their external environment - provide the tools to understand the direction in which markets are heading, profile local industry to determine what policy instruments can be most effective, and better understand how technology might evolve. Signals picked up today through an externally focused competitive intelligence effort can be used to confirm conclusions reached in longer term foresight initiatives such as scenarios, roadmaps and scans, thereby providing the information needed to establish the long-term industrial policy required by science and technology related industries.

\section{References}

Ashton B.W., Klavans R.A. (1997) Keeping Abreast of Science and Technology: Technical Intelligence for Business, Columbus, OH: Batelle Press.

Bergeron P. (2000) Government Approaches to Foster Competitive Intelligence Practice in SMEs: A Comparative Study of Eight Governments. Proceedings of the Annual Meeting - American Society for Information Science, vol. 37, pp. 301-308.

Bonthous J. (1995) Understanding intelligence across cultures. Competitive Intelligence Review (Summer/Fall), pp. 12-19.

Calof J. (2007) Event Intelligence: Time to Invite Your Government. Competitive Intelligence Magazine, vol. 10, no 5, pp. 55-57.

Calof J., Skinner B. (1999) What's Happening in Canada. Government's Role in Competitive Intelligence. Competitive Intelligence Magazine, vol. 2, no 2, pp. 20-23.

Calof J., Smith J. (2010) The integrative domain of foresight and competitive intelligence and its impact on R\&D management. $R \& D$ Management, vol. 40, no 1, pp. 31-39.

Davenport T., Harris J., Morrison R. (2010) Analytics at Work: Smarter Decisions, Better Results, Boston: Harvard Business School Press.

Dedijer S. (1994) Opinion: Governments, Business Intelligence - A Pioneering Report from France. Competitive Intelligence Review, vol. 5, no 3, pp. 45-47.

Du Toit A.S.A. (2013) Comparative Study of Competitive Intelligence Practices between Two Retail Banks in Brazil and South Africa. Journal of Intelligence Studies in Business, vol. 2, pp. 30-39.

Fleisher C.S., Bensoussan B. (2002) Strategic and competitive analysis: Methods and techniques for analyzing business, Upper Saddle River, NJ: Prentice Hall.

Fehringer D., Hohhof B., Johnson T. (2007) State of the art competitive intelligence, San Antonio, TX: Competitive Intelligence Foundation.

For-Learn (2014) Excerpt from online foresight guide. Available at: http://forlearn.jrc.ec.europa.eu/guide/9_key-terms/foresight. htm, accessed 20.06.2014.

Fruchet G. (2009) Effective practices for implementing CTI in large R\&D organizations in Competitive Technical Intelligence. The Competitive Technical Intelligence book, vol. 4 (eds. R. Ashton, B. Hohhof), San Antonio, TX: Competitive Intelligence Foundation, pp. 37-54.

GIA (2011) Market Intelligence in Global Organization: Survey Findings in 2011 (GIA White Paper 2/2011), Global Intelligence Alliance. GIA (2013) The State of Market Intelligence in 2013: Global MI Survey findings (GIA White Paper, 2013), Global Intelligence
Alliance.

Gilad B. (1998) Business Blindspots, New York: Irwin Professional Publishing.

Hamilton-Pennell C. (2004) CI For Small businesses: The City of Littleton's Economic Gardening program. Competitive Intelligence Magazine, vol. 7, no 6 (November-December), pp. 46-48.

Herring J. (1993) Business Intelligence: Scientific and Technical Intelligence: The Key to R\&D. Journal of Business Strategy, vol. 14, no 3 , pp. $10-12$

IBM (2013) Partnership for Public Service. From Data to Decisions III: Lessons from Early Analytics Programs, Washington, D.C.: IBM Centre for the Business of Government.

Kahaner L. (1997) Competitive Intelligence: How to Gather, Analyze, and Use Information to Move Your Business to the Top, New York: Simon \& Schuster.

Juhari A., Stephens D. (2006) Tracing the origins of competitive intelligence throughout history. Competitive Intelligence Review, vol. 3, no 4, pp. 61-82.

Office of the Director of National Intelligence (2014) Foresight and understanding from scientific exposition (FUSE). Available at: http://www.iarpa.gov/index.php/research-programs/fuse, accessed 20.06.2014.

Parker D. (2000) Can Government CI Bolster Regional Competitiveness? Competitive Intelligence Review, vol. 11, no 4, pp. 57-64.

Popper R. (2008) How are foresight methods selected? Foresight, vol. 10, no 6, pp. 62-89.

Provost F., Fawcett T. (2013) Data Science for Business: What you need to know about data mining and data-analytic thinking,

Salvador M.R., Salinas Casanova L.F. (2013) Applying Competitive Intelligence: The Case of Thermoplastics Elastomers. Journal of Intelligence Studies in Business, vol. 3, pp. $47-53$.

Saritas O., Smith J. (2008) Big Picture Foresight Survey Results and Implications. Paper presented at Future-oriented Technology Analysis (FTA) Conference 2008, Seville.

SCIP (2004) Proceedings: 9th Annual European Conference, 27-29 October, Milan, Italy, San-Antonio, TX: Society of Competitive Intelligence Professionals.

SCIP (2014) FAQ's. Available at: www.scip.org/re pdfs/1395928684_pdf_FrequentlyAskedQuestions.pdf, accessed 17.06.2014.

Smalla H., Boyack K., Klavans R. (2014) ldentifying emerging topics in science and technology. Research Policy, vol. 43, no 8, pp. $1450-1467$.

Smith J., Saritas O. (2011) Science and technology foresight baker's dozen: A pocket primer of comparative and combined foresight methods. Foresight, vol. 13, no 2, pp. 79-96.

Watson K. (1997) Intelligence gathering: Scanning, mind maps and scenarios. Optimum, vol. 27, no 2, pp. 69-74.

Wolfe J. (2005) Safer and guilt-free nano foods. Forbes Magazine, September 8. Available at: www.forbes.com/2005/08/09/ nanotechnology-kraft-hershey-cz_jw_0810soapbox_inl.html, accessed 20.06.2014.

Wright S., Calof Y. (2006) The Quest for Competitive Business and Marketing Intelligence: A Country Comparison of Current Practices. European Journal of Marketing, vol. 40, no 5-6, pp. 453-465.

Xu K., Liao S.S., Ki J., Song Y. (2011) Mining comparative opinions from customer reviews for competitive intelligence. Decision Support Systems, vol. 50, no 4, pp. 743-754. 